\title{
Extracorporeal shock wave lithotripsy is safe and effective for pediatric patients with chronic pancreatitis $\square$
}

\section{다 (1)}

\author{
Authors \\ Dan Wang ${ }^{*}$, , Ya-Wei Bi ${ }^{*}, 1$, Jun-Tao $\mathrm{Ji}^{*}{ }^{, 2}$, Lei Xin', \\ Jun Pan ${ }^{1}$, Zhuan Liao ${ }^{1,2}$, Ting-Ting Du ${ }^{1}$, Jin-Huan Lin¹, \\ Di Zhang ${ }^{1}$, Xiang-Peng Zeng ${ }^{1}$, Bo Ye ${ }^{3}$, Wen-Bin Zou' ${ }^{1}$, Hui \\ Chen ${ }^{2}$, Ting $\mathrm{Xie}^{4}$, Bai-Rong Li ${ }^{5}$, Zhao-Hong Zheng ${ }^{6}$, Zhao- \\ Shen $\mathrm{Li}^{1}{ }^{1,2}$, Liang-Hao $\mathrm{Hu}^{1,2}$ \\ Institutions \\ 1 Department of Gastroenterology, Changhai Hospital, \\ The Second Military Medical University, Shanghai, China \\ 2 Digestive Endoscopy Center, Changhai Hospital, The \\ Second Military Medical University, Shanghai, China \\ 3 Department of Surgery, Jinling Hospital, Nanjing, China \\ 4 Department of Gastroenterology, Zhongda Hospital, \\ Southeast University, Nanjing, China \\ 5 Department of Gastroenterology, Air Force General \\ Hospital, Beijing, China \\ 6 Department of Traditional Chinese Medicine, Jiangdu \\ Hospital, Yangzhou, China
}

submitted 23.9.2016

accepted after revision 6.2 .2017

Bibliography

DOI http://dx.doi.org/10.1055/s-0043-104527

Published online: 12.4.2017 | Endoscopy 2017; 49: 447-455

(c) Georg Thieme Verlag KG Stuttgart · New York ISSN 0013-726X

Corresponding author

Liang-Hao Hu, MD or Zhao-Shen Li, MD, Department of Gastroenterology, Digestive Endoscopy Center, Changhai Hospital, The Second Military Medical University, 168

Changhai Road, Shanghai 200433, China

Fax: +86-21-55621735

lianghao-hu@hotmail.com

zhaoshen-li@hotmail.com
丹 Scan this QR-Code to watch the video comment.

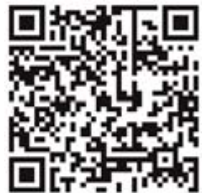

\section{ABSTRACT}

Background and aims Pancreatic extracorporeal shock wave lithotripsy (P-ESWL) is recommended as the first-line treatment for pancreatic stones. However, how well PESWL performs in pediatric patients remains unclear. We aimed to evaluate the safety and efficacy of P-ESWL for pediatric patients with chronic pancreatitis.

Methods This prospective observational study was conducted in patients with painful chronic pancreatitis who underwent P-ESWL. Patients aged under 18 years were included in the pediatric group; patients aged over 18 years who underwent P-ESWL in the same period were assigned to the control group. For investigation of long-term follow-up, the pediatric group were matched with patients from the control group in a 1:1 ratio. The primary outcomes were $\mathrm{P}$ ESWL complications and pain relief. The secondary outcomes included: stone clearance, physical and mental health, quality of life score, and growth and developmental state.

Results From March 2011 to March 2015, P-ESWL was performed in 1135 patients (72 in the pediatric group, 1063 in the control group). No significant differences were observed in the occurrence of P-ESWL complications between the two groups ( $11.1 \%$ vs. $12.8 \% ; P=0.68)$. Among the 67 pediatric patients $(93.1 \%)$ who underwent follow-up for 3.0 years (range $1.3-5.2$ ), complete pain relief was achieved in 52 patients $(52 / 67 ; 77.6 \%)$; this value was not significantly different from that of the matched controls (55/69; 79.7\%; $P=0.94)$.

Conclusions P-ESWL is safe and effective for pediatric patients with chronic pancreatitis. It can promote significant pain relief and stone clearance, and can benefit growth and development.

\section{Introduction}

Chronic pancreatitis is characterized by pancreatic inflammation and fibrosis, which eventually leads to the destruction of the pancreatic parenchyma and loss of both exocrine and endocrine function.

\footnotetext{
* Contributed equally to this study.
}

Recent studies have estimated that the incidence of chronic pancreatitis in children is approximately 0.5 per 100000 per year [ $1-3]$. Despite this modest incidence rate, the disease burden of chronic pancreatitis in pediatric patients is substantial owing to the extreme disruption caused to the patients' childhood and education. Children with chronic pancreatitis typically suffer from chronic or severe relapsing abdominal pain, with frequent emergency department visits, hospitalizations, and 
school absences [4]. Moreover, malnutrition caused by decreased dietary intake and malabsorption is known to retard the growth and development of these children [5].

Pain control is the mainstay of chronic pancreatitis management. Characteristic pathological changes, such as pancreatic duct stricture and stones, lead to intraductal hypertension, which is the most important factor for abdominal pain. Pancreatic stones are present in $50 \%$ of patients with chronic pancreatitis and $12 \%-69.7 \%$ of pediatric patients with chronic pancreatitis [4,6-9]. Treatment of pancreatic stones in adults is standardized, with guidelines available; surgery and endoscopy represent the first-line therapies [10]. However, a consensus regarding the treatment strategy for pediatric patients with chronic pancreatitis is not available [11]. According to previous studies, for pediatric chronic pancreatitis coexisting with pancreatic stones, surgery and endoscopy are also considered safe and effective therapies [12-15]. Because of the irreversibility of the disease, children with pancreatic stones have a higher risk of recurrence over a longer period of time than adults, therefore indicating a higher cumulative likelihood of stone recurrence throughout their lives.

Pancreatic extracorporeal shock wave lithotripsy (P-ESWL) is minimally invasive, effective, and safe for the management of adults with pancreatic stones and does not impede subsequent endoscopy or surgery in patients with recurrent stones in the future. However, the safety and efficacy of P-ESWL in pediatric patients has not been previously reported.

The main concern with regard to the application of P-ESWL in pediatric patients is the potential for complications of the procedure, such as acute pancreatitis, perforation, bleeding, infection, and anesthesia-related side effects. The aim of our study was to evaluate the safety and efficacy of P-ESWL in the treatment of pediatric patients with pancreatic stones.

\section{Patients and methods}

\section{Study design}

We performed a prospective cohort study to evaluate the outcome of pediatric patients with pancreatic stones who underwent P-ESWL in comparison to the outcome of all adult patients who underwent P-ESWL within the same period. Written informed consent was obtained from each patient, and the study was approved by the Ethics Committee of Changhai Hospital. Informed consent for patients aged less than 18 years was provided by their guardian.

\section{Patients and data collection}

The target population for P-ESWL was patients with painful chronic pancreatitis and radiopaque stones of $\geq 5 \mathrm{~mm}$. Patients with a suspected or established malignant mass or pancreatic ascites, and pregnant patients were not considered for the PESWL treatment. The diagnosis of chronic pancreatitis was established primarily based on computed tomography (CT), magnetic resonance imaging (MRI), or endoscopic ultrasound (EUS) examinations according to the Asia-Pacific consensus [16]. All of the patients were evaluated with CT scans prior to P-ESWL.
Patients aged less than 18 years who underwent P-ESWL treatment from March 2011 to March 2015 were included in the pediatric group, whereas patients older than 18 years who underwent P-ESWL treatment in the same period were assigned to the control group. Demographic data and the disease course of the chronic pancreatitis, including the onset, manifestations, diagnosis, and previous treatments, were recorded in detail upon admission to the hospital. In addition, the visual analog scale (VAS) pain score, quality of life score, and Medical Outcomes Study 36-Item Short-Form General Health Survey (SF36) questionnaire were completed.

To evaluate the long-term outcomes of P-ESWL in pediatric patients, we matched the pediatric group with patients from the control group in a 1:1 ratio. The matching principles were sex, type of abdominal pain, and location of the stone(s).

For patients in the pediatric group and patients selected as the matched controls, revisits were required annually after PESWL therapy. During the revisits, contrast-enhanced CT of the pancreas was performed, and follow-up data, including the disease course of the chronic pancreatitis after P-ESWL, VAS pain score, usage of medication, disease-related inability to work, quality of life score, and SF-36 questionnaire, were recorded. In June 2016, we evaluated the patients in the pediatric group and the matched controls included in this study.

\section{Treatment strategy}

In this study, all of the patients involved were treated with PESWL after admission to the hospital. P-ESWL was performed using a third-generation electromagnetic lithotripter (Compact Delta II; Dornier Med Tech, Wessling, Germany). After they had received intravenous sedation analgesia (flurbiprofen combined with remifentanil), the patients were treated in the supine position with the shock head touching the abdomen from above. Pancreatic duct stones were targeted by the lithotripter using fluoroscopy.

For each individual patient, the P-ESWL session was repeated on consecutive days until the stone was fragmented to $\leq 3 \mathrm{~mm}$ in diameter. No more than 5000 shocks at an intensity of $6(16000 \mathrm{kV})$ on a scale of $1-6$, at a frequency of 120 shocks/min were delivered during each therapeutic session. The duration of each session was $60-90$ minutes $[17,18]$. Radiation protection was provided by adhering to the European Society of Gastrointestinal Endoscopy (ESGE) guidelines [19]. For patients in the pediatric group, a pancreatic surgery team was on call during the study in case of severe complications.

Endoscopic retrograde cholangiopancreatography (ERCP) was routinely performed 48 hours after the last P-ESWL ( $\triangleright$ Video 1, $\triangleright$ Fig. 1). The treatment principle for the ERCP mainly followed the ESGE guidelines [11].

\section{Outcome measures}

A standardized evaluation of symptoms and investigations was carefully performed after every P-ESWL session and after the ERCP that was performed post-ESWL. Any complications and relevant treatments were documented during the subsequent 30 days after P-ESWL and ERCP. 
- Table 1 Definitions of major complications of pancreatic extracorporeal shock wave lithotripsy (P-ESWL).

\begin{tabular}{|c|c|c|c|}
\hline Complications $^{1}$ & Mild & Moderate & Severe \\
\hline Post-ESWL pancreatitis & $\begin{array}{l}\text { Clinical pancreatitis, amylase at } \\
\text { least three times the normal level> } \\
24 \text { hours after the procedure, re- } \\
\text { quiring admission or extension of } \\
\text { planned admission from } 2 \text { days to } 3 \\
\text { days }\end{array}$ & $\begin{array}{l}\text { Requiring hospitalization of } \\
4-10 \text { days }\end{array}$ & $\begin{array}{l}\text { Hospitalization for }>10 \text { days, pseu- } \\
\text { docyst, or intervention (percuta- } \\
\text { neous drainage or surgery) }\end{array}$ \\
\hline Bleeding ${ }^{2}$ & $\begin{array}{l}\text { Clinical evidence of bleeding, he- } \\
\text { moglobin drop }<3 \mathrm{~g} \text {, no transfusion } \\
\text { required }\end{array}$ & $\begin{array}{l}\text { Transfusion ( } \leq 4 \text { units), no angio- } \\
\text { graphic intervention, or surgery }\end{array}$ & $\begin{array}{l}\text { Transfusion of } \geq 5 \text { units or interven- } \\
\text { tion (angiographic or surgical) }\end{array}$ \\
\hline Infection & $\begin{array}{l}\text { Temperature }>38 \mathrm{C} \text { for } 24-48 \\
\text { hours }\end{array}$ & $\begin{array}{l}\text { Requiring }>3 \text { days of hospital } \\
\text { treatment }\end{array}$ & $\begin{array}{l}\text { Abscess, septic shock, or interven- } \\
\text { tion (percutaneous drainage or } \\
\text { surgery) }\end{array}$ \\
\hline Steinstrasse ${ }^{3}$ & $\begin{array}{l}\text { Severe abdominal pain without } \\
\text { other post-ESWL complications }\end{array}$ & $\begin{array}{l}\text { Combined with other complica- } \\
\text { tions, or requiring }>3 \text { days of } \\
\text { hospital treatment }\end{array}$ & $\begin{array}{l}\text { Combined with other complica- } \\
\text { tions; hospitalization for }>10 \text { days, } \\
\text { or surgery }\end{array}$ \\
\hline Perforation & $\begin{array}{l}\text { Possible, or very slight, leak of fluid, } \\
\text { treatable with fluids and suction } \\
\text { for } \leq 3 \text { days }\end{array}$ & $\begin{array}{l}\text { Any definite perforation treated } \\
\text { medically for } 4-10 \text { days }\end{array}$ & $\begin{array}{l}\text { Medical treatment for }>10 \text { days or } \\
\text { intervention (percutaneous or } \\
\text { surgical) }\end{array}$ \\
\hline \multicolumn{4}{|c|}{$\begin{array}{l}{ }^{1} \text { Splenic rupture, pancreaticobiliary fistula, and other rare complications were not included in this classification of complications. } \\
2 \text { Acute gastrointestinal mucosal injury was not included, but was classified as a transient adverse event. } \\
{ }^{3} \text { Steinstrasse refers to: acute stone incarceration in the papilla leading to poor pancreatic juice drainage; computed tomography scan showing a more dilated pan- } \\
\text { creatic duct with/without acute pancreatitis; severe abdominal pain that cannot be relieved by analgesics but can be relieved by emergency endoscopic retrograde } \\
\text { cholangiopancreatography (ERCP) or ESWL. }\end{array}$} \\
\hline
\end{tabular}

The primary outcomes were complications of P-ESWL [17] ( $\triangleright$ Table 1) and pain relief. Secondary outcomes were: stone clearance, growth and development, physical and mental health, quality of life score, and changes in exocrine and endocrine pancreatic function.

\section{VIDEO 1}
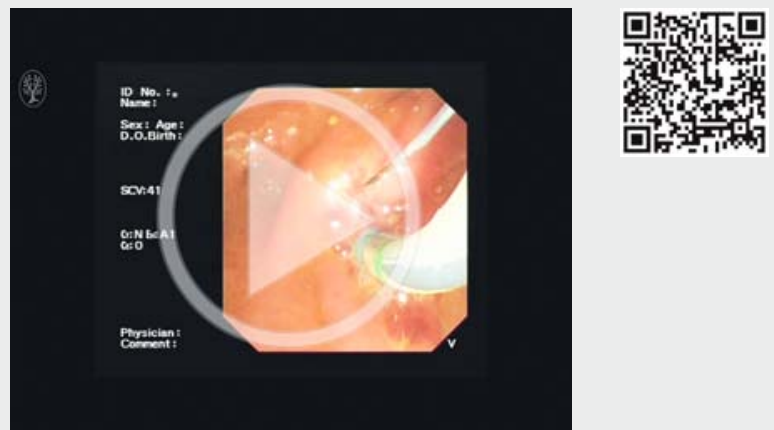

- Video 1: After repeated pancreatic extracorporeal shock wave lithotripsy (ESWL) sessions, radiographic examinations indicated that the pancreatic stones were fragmented to $\leq 3 \mathrm{~mm}$ in size and located in the pancreatic head. Endoscopic retrograde cholangiography revealed a normal bile duct, whereas endoscopic retrograde pancreatography revealed a large number of stones in the dilated pancreatic duct. After sphincterotomy, balloon sphincteroplasty was performed, and the orifice of the pancreatic duct was dilated to $1.0 \mathrm{~cm}$. The stones were removed by basket extraction. Online content viewable at: https://www.thieme-connect.com/ DOI/DOI?10.1055/s-0043-104527
Pain relief at the end of the follow-up period was classified as complete relief (Izbicki pain score $\leq 10$ ) or partial relief (Izbicki pain score $>10$ after a decrease of $>50 \%$ ) [20, 21]. Stone clearance was evaluated at the ERCP performed post-ESWL, with complete clearance defined as clearance of $>90 \%$ of the main pancreatic duct (MPD) stone volume, whereas partial clearance was defined as clearance of $50 \%-90 \%$ of the stone volume. Quality of life scores were assessed by the patient and ranged from 0 to 100, with higher scores indicating a better quality of life [22]. Physical and mental health were assessed according to the scores on the SF-36 questionnaire.

\section{Statistical analysis}

Depending on the distributional properties, outcome measures were expressed as the mean \pm standard deviation (SD) or as median values with ranges. For normally distributed continuous data, statistical significance was assessed by the Student's $t$ test; for categorical data, significance was assessed by the chisquared test with Yates' correction when appropriate or by the Fisher's exact test; and for non-normally distributed continuous data, statistical significance was assessed by the Wilcoxon test. All reported $P$ values are two-sided. A $P$ value of $<0.05$ was established as the significance level. Missing follow-up data were considered to be missing at random.

\section{Results}

From March 2011 to March 2015, P-ESWL was performed in 1135 patients (72 in the pediatric group and 1063 in the control group). 

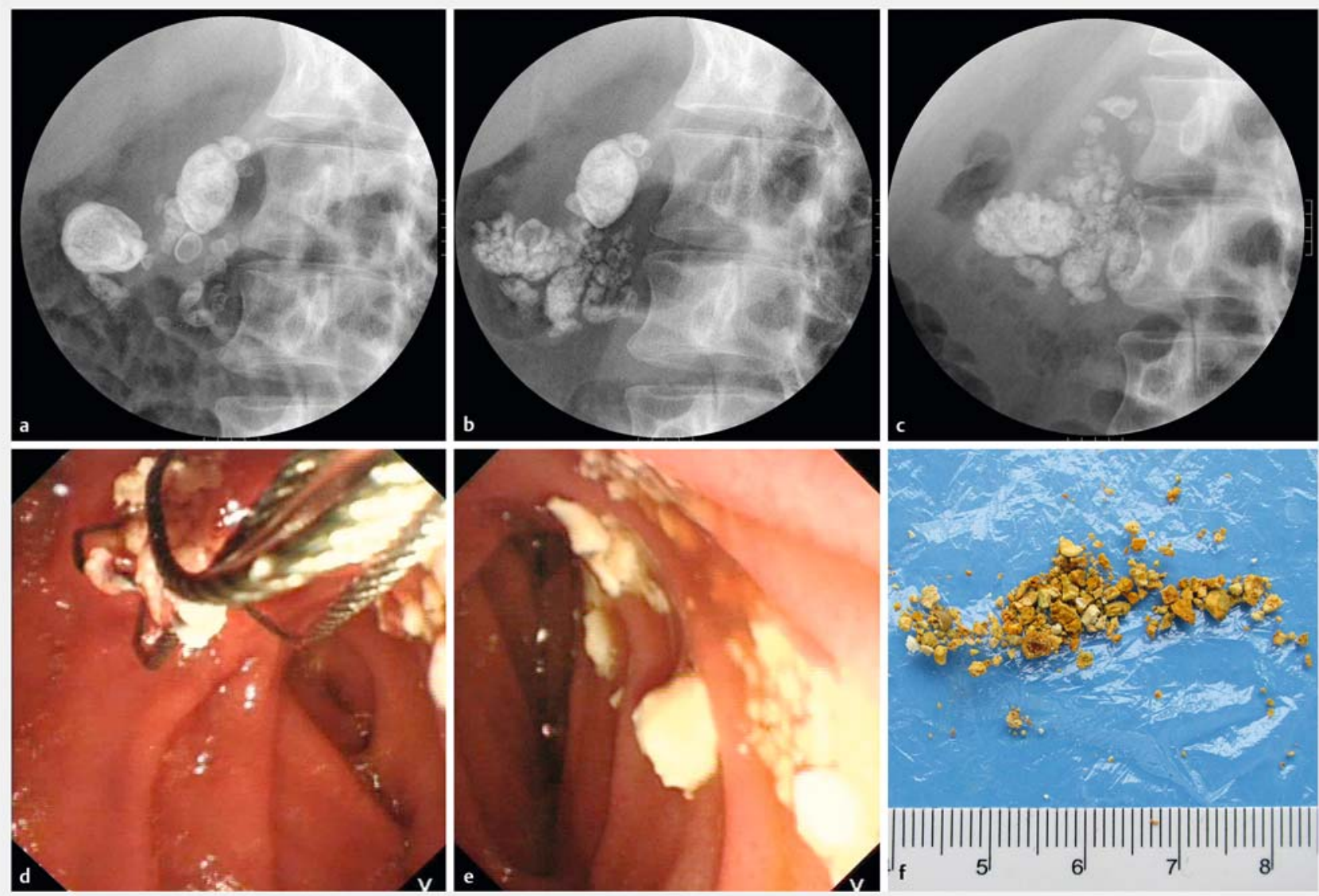

Fig. 1 The process of pancreatic stone fragmentation and extraction. a A fluoroscopic image showing multiple stones in the head of pancreas before P-ESWL. The image was taken with the patient in a supine position tilting to right in an angle of $30^{\circ}$. $\mathbf{b}$ As shown in the X-ray. Parts of the stones were fragmented after the first P-ESWL. c After the second P-ESWL, the pulverized stones were less dense than they were prior to P-ESWL and spread all along the duct. The patient then received a third P-ESWL followed by ERCP. $\mathbf{d}$ During ERCP, plenty of white pulverized stones were extracted by extraction basket. e An endoscopic image showing extracted pulverized calculi. $\mathbf{f}$ Pancreatic stones identified from the stool of the patient.

\section{Baseline characters}

The demographic and clinical characteristics of the patients in the two groups differed significantly. Compared with the control group, the percentage of male subjects was lower in the pediatric group (56.9\% vs. $72.8 \%$; $P=0.004$ ). Regarding the etiology, more pediatric patients were classified as having idiopathic chronic pancreatitis (ICP; $95.8 \%$ vs. 69.4\%; $P<0.001$ ). The pediatric group also had a lower prevalence of diabetes mellitus (5.6\% vs. $29.8 \% ; P<0.001)$ and steatorrhea $(5.6 \%$ vs. $26.0 \% ; P<0.001)$ ( $>$ Table 2 ).

The age of the pediatric patients who underwent P-ESWL was $15.2 \pm 2.2$ years (range $8.0-18.0$ years). Compared with the control group, the interval time from the diagnosis of pancreatic stones to P-ESWL being performed was shorter in the pediatric group (median 0.19 years vs. 0.5 years; $P=0.02$ ). $P$ diatric patients were subjected to fewer P-ESWL sessions (median 1.0 vs. $2.0 ; P<0.001)$ and fewer shocks $(8265 \pm 4918$ vs. $11231 \pm 7247 ; P<0.001)$ per person compared with the control group patients ( $\triangleright$ Table 3 ).

\section{Safety}

No significant differences were observed between the pediatric and control groups regarding the overall and specific complications of P-ESWL (11.1\% vs. $12.8 \% ; P=0.68$ ) ( $\triangleright$ Table 4$)$. In the pediatric group, eight complications of P-ESWL occurred in eight patients $(8 / 72 ; 11.1 \%)$, with five of these patients presenting with mild post-ESWL pancreatitis (PEP), two presenting with moderate PEP, and one presenting with mild steinstrasse.

All of the patients were referred for ERCP. No significant differences were observed between the pediatric group (4/72; $5.6 \%)$ and control group $(40 / 1063 ; 3.8 \%)$ in terms of postERCP complications $(P=0.36)$.

\section{Efficacy}

During the ERCP performed post-ESWL, complete clearance of the stones was achieved in $86.1 \%$ of the patients in the pediatric group (62/72) and $94.4 \%$ in the matched controls (68/72; $P=0.07)$ ( $>$ Table 5).

The median follow-up period was 3.0 years (range $1.3-5.2$ years) for the pediatric group and 2.8 years ( $1.4-5.0$ years) for 
- Table 2 General characteristics of the pediatric group and the control group.

\begin{tabular}{|c|c|c|c|}
\hline & Pediatric group $(n=72)$ & Control group $(n=1063)$ & $P$ value \\
\hline Mean age $\pm S D$ at onset of chronic pancreatitis, years & $9.9 \pm 4.8$ & $37.0 \pm 14.1$ & $<0.001$ \\
\hline Mean age \pm SD at diagnosis of chronic pancreatitis, years & $14.0 \pm 3.5$ & $42.8 \pm 13.0$ & $<0.001$ \\
\hline Mean age \pm SD at which stone(s) were identified, years & $14.1 \pm 3.5$ & $43.0 \pm 12.8$ & $<0.001$ \\
\hline Male sex, n (\%) & $41(56.9 \%)$ & $774(72.8 \%)$ & 0.004 \\
\hline Alcohol, n (\%) & $1(1.4 \%)$ & $521(49.0 \%)$ & $<0.001$ \\
\hline Smoking, n (\%) & $1(1.4 \%)$ & $558(52.5 \%)$ & $<0.001$ \\
\hline \multicolumn{3}{|l|}{ Etiology, n (\%) } & \multirow[t]{4}{*}{$<0.001$} \\
\hline - Alcoholic chronic pancreatitis & 0 & $280(26.3 \%)$ & \\
\hline - Idiopathic chronic pancreatitis ${ }^{1}$ & $69(95.8 \%)$ & $738(69.4 \%)$ & \\
\hline - Others ${ }^{2}$ & $3(4.2 \%)$ & $45(4.2 \%)$ & \\
\hline \multicolumn{3}{|l|}{ Symptoms of chronic pancreatitis onset, n (\%) } & \multirow[t]{4}{*}{0.001} \\
\hline - Abdominal pain & $68(94.4 \%)$ & $810(76.2 \%)$ & \\
\hline - Diabetes mellitus/steatorrhea & $4(5.6 \%)$ & $192(18.1 \%)$ & \\
\hline " Others & 0 & $61(5.7 \%)$ & \\
\hline \multicolumn{3}{|l|}{ Type of abdominal pain, $\mathrm{n}(\%)$} & \multirow[t]{5}{*}{0.16} \\
\hline - Recurrent acute pancreatitis & $16(22.2 \%)$ & $361(34.0 \%)$ & \\
\hline $\begin{array}{l}\text { - Recurrent abdominal pain without significantly increased } \\
\text { serum amylase }\end{array}$ & $21(29.2 \%)$ & $293(27.6 \%)$ & \\
\hline $\begin{array}{l}\text { - Recurrent acute pancreatitis and abdominal pain without } \\
\text { significantly increased serum amylase }\end{array}$ & $29(40.3 \%)$ & $319(30.0 \%)$ & \\
\hline - Chronic pancreatic pain & $6(8.3 \%)$ & $90(8.5 \%)$ & \\
\hline Severe acute pancreatitis, n (\%) & $1(1.4 \%)$ & $30(2.8 \%)$ & 0.41 \\
\hline Diabetes mellitus, n (\%) & $4(5.6 \%)$ & $317(29.8 \%)$ & $<0.001$ \\
\hline Steatorrhea, n (\%) & $4(5.6 \%)$ & $276(26.0 \%)$ & $<0.001$ \\
\hline Common bile duct stenosis, n (\%) & 0 & $95(8.9 \%)$ & 0.008 \\
\hline Pancreatic pseudocyst, n (\%) & $11(15.3 \%)$ & $145(13.6 \%)$ & 0.70 \\
\hline \multicolumn{3}{|l|}{ Location of stone(s), n (\%) } & \multirow[t]{4}{*}{0.45} \\
\hline - Head & $48(66.7 \%)$ & 760 (71.5\%) & \\
\hline - Body/tail & $1(1.4 \%)$ & $28(2.6 \%)$ & \\
\hline - Head and at least another location & $23(31.9 \%)$ & $275(25.9 \%)$ & \\
\hline \multicolumn{4}{|c|}{$\begin{array}{l}\text { SD, standard deviation. } \\
1 \text { Whether pancreatic divisum and anomalous pancreaticobiliary junction are etiologies of chronic pancreatitis is disputable. Herein, these features are included un- } \\
\text { der idiopathic chronic pancreatitis. } \\
{ }^{2} \text { Includes hereditary chronic pancreatitis, pancreatic trauma, pancreatic anatomical abnormality, and hyperlipidemia. Among the pediatric patients, there was one } \\
\text { case of hereditary chronic pancreatitis and two of pancreatic trauma. In the control group, there were } 17 \text { cases of hereditary pancreatitis, } 24 \text { of pancreatic anato- } \\
\text { mical abnormalities, two of pancreatic trauma, and two of hyperlipidemia. }\end{array}$} \\
\hline
\end{tabular}

the matched controls. Five patients in the pediatric group and 3/72 matched controls were lost to follow-up. Among the 67 patients $(93.1 \%)$ receiving ongoing follow-up in the pediatric group, complete pain relief was achieved in 52 patients (52/ $67 ; 77.6 \%)$, and significant differences were not observed compared with the matched controls (55/69; 79.7\%; $P=0.94$ ) ( $>$ Table6). Four pediatric patients and one matched control later underwent surgery because of poor outcomes after endoscopic therapy. One of the four underwent resection of a pancreatic pseudocyst combined with longitudinal pancreaticojejunostomy (LPJ) because of the enlarged pseudocyst; the other three patients underwent LPJ because of unrelieved pain. The one matched control who needed surgery underwent pancreatic tail resection plus splenectomy because of gastric variceal bleeding. 
- Table 3 Details of pancreatic extracorporeal shock wave lithotripsy (P- ESWL).

\begin{tabular}{|c|c|c|c|}
\hline & Pediatric group $(n=72)$ & Control group $(n=1063)$ & $P$ value \\
\hline Mean age \pm SD at performance of ESWL, years & $15.2 \pm 2.2$ & $44.7 \pm 12.5$ & $<0.001$ \\
\hline $\begin{array}{l}\text { Mean time } \pm S D \text { from onset of chronic pancreatitis to ESWL, } \\
\text { years }\end{array}$ & $5.3 \pm 4.3$ & $7.8 \pm 7.6$ & $<0.001$ \\
\hline $\begin{array}{l}\text { Median time (range) from identification of stone(s) to ESWL, } \\
\text { years }\end{array}$ & $\begin{array}{l}0.19 \\
(0.0-10.0)\end{array}$ & $\begin{array}{l}0.5 \\
(0.0-23.2)\end{array}$ & 0.02 \\
\hline Mean number of shocks \pm SD & $8265 \pm 4918$ & $11231 \pm 7247$ & $<0.001$ \\
\hline Median number of ESWL sessions (range) & $\begin{array}{l}1.0 \\
(1.0-5.0)\end{array}$ & $\begin{array}{l}2.0 \\
(1.0-12.0)\end{array}$ & $<0.001$ \\
\hline
\end{tabular}

- Table 4 Pancreatic extracorporeal shock wave lithotripsy (P-ESWL) complications in the pediatric and control groups.

\begin{tabular}{|l|l|l|l|}
\hline Complications & $\begin{array}{l}\text { Pediatric } \\
\text { group (n=72) }\end{array}$ & $\begin{array}{l}\text { Control group } \\
(\mathbf{n = 1 0 6 3 )}\end{array}$ & P value \\
\hline Type, n (\%) & & & \\
\hline - PEP & $7(9.7 \%)$ & $98(9.2 \%)$ & 0.89 \\
\hline - Infection & 0 & $17(1.6 \%)$ & 0.62 \\
\hline - Bleeding & 0 & $5(0.5 \%)$ & 1.00 \\
\hline - Perforation & 0 & $7(0.7 \%)$ & 1.00 \\
\hline - Steinstrasse & $1(1.4 \%)$ & $7(0.7 \%)$ & 0.41 \\
\hline - Others & 0 & $2(0.2 \%)$ & 1.00 \\
\hline Severity, n (\%) & & $113(10.6 \%)$ & 0.80 \\
\hline - Mild & $6(8.3 \%)$ & $20(1.9 \%)$ & \\
\hline - Moderate & $2(2.8 \%)$ & $3(0.3 \%)$ & 0.68 \\
\hline - Severe & 0 & $136(12.8 \%)$ & \\
\hline Total complica- & $8(11.1 \%)$ & & \\
\hline PEP, post-ESWL pancreatitis. & & & \\
\hline
\end{tabular}

In the pediatric group, the pain frequency $(P<0.001)$, VAS pain score $(P<0.001)$, and absences from school (median 40.0 days vs. 0.0 days; $P<0.001)$ decreased significantly, and the scores for quality of life $(60.4 \pm 20.7$ vs. $83.7 \pm 11.3 ; P<0.001)$ and physical health based on the SF-36 (63.8 \pm 16.9 vs. $72.9 \pm$ $15.1 ; P=0.03)$ improved after the P-ESWL. No differences were observed in the mental health scores $(68.0 \pm 14.7$ vs. $71.7 \pm$ $11.1 ; P=0.31$ ) before and after P-ESWL. The weight, height, and body mass index (BMI) of the pediatric patients improved significantly at follow-up ( $>$ Table 7 ).

The height of the boys in the pediatric group pre-ESWL was significantly lower compared with the standard heights for their ages $(P=0.009)$, and similar results were obtained for the girls $(P<0.001)$. At the end of follow-up, the heights of the boys resembled the standard heights for their ages $(P=0.06)$; however, similar effects were not noted for the girls $(P=0.02)$ ( Fig. 2).
- Table 5 Findings and procedural characteristics of ERCP after pancreatic extracorporeal shock wave lithotripsy (P-ESWL).

\begin{tabular}{|c|c|c|c|}
\hline & $\begin{array}{l}\text { Pediatric } \\
\text { group }(n=72)\end{array}$ & $\begin{array}{l}\text { Matched con- } \\
\text { trols }(n=72)\end{array}$ & $P$ value \\
\hline $\begin{array}{l}\text { MPD stricture, } \\
\mathrm{n}(\%)\end{array}$ & 35 (48.6\%) & $42(58.3 \%)$ & 0.24 \\
\hline \multicolumn{4}{|l|}{$\begin{array}{l}\text { ERCP procedure, } \\
n(\%)\end{array}$} \\
\hline $\begin{array}{l}\text { - Endoscopic } \\
\text { papillotomy }\end{array}$ & $41(56.9 \%)$ & $46(63.9 \%)$ & 0.34 \\
\hline - Bougie dilation & $16(22.2 \%)$ & $16(22.2 \%)$ & 1.00 \\
\hline $\begin{array}{l}\text { - Balloon } \\
\text { dilation }\end{array}$ & $16(22.2 \%)$ & $21(29.1 \%)$ & 0.34 \\
\hline $\begin{array}{l}\text { - Stone } \\
\text { extraction }\end{array}$ & $56(77.8 \%)$ & $60(83.3 \%)$ & 0.40 \\
\hline $\begin{array}{l}\text { - Pancreatic } \\
\text { stent }\end{array}$ & $34(47.2 \%)$ & $27(37.5 \%)$ & 0.24 \\
\hline $\begin{array}{l}\text { - Successful } \\
\text { drainage }\end{array}$ & $65(90.3 \%)$ & $68(94.4 \%)$ & 0.17 \\
\hline $\begin{array}{l}\text { Stone clearance, } \\
\mathrm{n}(\%)\end{array}$ & & & 0.07 \\
\hline - Complete ${ }^{1}$ & $62(86.1 \%)$ & $68(94.4 \%)$ & \\
\hline - Partial $\left.\right|^{2}$ & $9(12.5 \%)$ & $2(2.8 \%)$ & \\
\hline - Failed ${ }^{3}$ & $1(1.4 \%)$ & $2(2.8 \%)$ & \\
\hline \multicolumn{4}{|c|}{$\begin{array}{l}\text { MPD, main pancreatic duct; ERCP, endoscopic retrograde cholangiopan- } \\
\text { creatography. } \\
1 \text { Clearance of }>90 \% \text { of MPD stone volume. } \\
{ }^{2} \text { Clearance of } 50 \%-90 \% \text { of MPD stone volume. } \\
{ }^{3} \text { Clearance of }<50 \% \text { of MPD stone volume. }\end{array}$} \\
\hline
\end{tabular}

\section{Discussion}

P-ESWL has been successfully applied in the treatment of pancreatic stones since 1987 and is now recommended as the first-line therapy for adult patients with uncomplicated painful chronic pancreatitis and radiopaque stones $\geq 5 \mathrm{~mm}$ obstructing the MPD [11]. The safety and efficacy of P-ESWL have been 
- Table6 Pain relief and further treatment at follow-up.

\begin{tabular}{|c|c|c|c|}
\hline & $\begin{array}{l}\text { Pediatric } \\
\text { group } \\
(n=67)\end{array}$ & $\begin{array}{l}\text { Matched } \\
\text { controls } \\
(n=69)\end{array}$ & $P$ value \\
\hline Pain relief, n (\%) & & & 0.94 \\
\hline - Complete ${ }^{1}$ & $52(77.6)$ & 55 (79.7) & \\
\hline - Partial ${ }^{2}$ & $8(11.9)$ & $8(11.6)$ & \\
\hline - No & $7(10.4)$ & $6(8.7)$ & \\
\hline Further $\operatorname{ERCP}(\mathrm{s})^{3}, \mathrm{n}(\%)$ & $20(29.9)$ & $13(18.8)$ & 0.13 \\
\hline Further surgery, n (\%) & $4(6.0)$ & $1(1.4)$ & 0.35 \\
\hline \multicolumn{4}{|c|}{$\begin{array}{l}\text { ERCP, endoscopic retrograde cholangiopancreatography. } \\
1 \text { Izbicki pain score } \leq 10 \text {. } \\
2 \text { Izbicki pain score }>10 \text { after a decrease of }>50 \% \text {. }\end{array}$} \\
\hline
\end{tabular}

demonstrated in numerous studies; however, data for pediatric patients have not been previously reported [22-25]. In clinical studies of pediatric ERCP $[8,26]$, a proportion of the children were subjected to P-ESWL; however, the outcomes of the PESWL subgroup were not evaluated. Our study is the first to report that P-ESWL is a safe and effective treatment for pediatric patients with pancreatic stones. The risk of complications relating to P-ESWL was not increased in pediatric patients, and the efficacy of P-ESWL was demonstrated by the significant pain relief and effective stone clearance. The outcome was similar to the results of previous P-ESWL studies in adults $[22,23,27,28]$.

The etiology of chronic pancreatitis in pediatric patients is different from that in adults, with environmental factors, such as alcohol use and smoking, rarely affecting pediatric patients. In this study, $95.8 \%$ of patients in the pediatric group had ICP, and male patients were less predominant than in the control group. In fact, increasing evidence suggests that the contribution of genetic or hereditary causes has been underestimated and this may be responsible for a significant proportion of cases previously diagnosed as idiopathic [29].

Compared with the control group, the pediatric patients required fewer shock waves in their P-ESWL to achieve successful stone fragmentation. This result may be attributed to the reduced time from stone diagnosis to P-ESWL in the pediatric patients, which likely corresponded to the newly emerging stones having a softer texture and being of a smaller size. Another possible reason is that the distance between the skin and the stone is shorter in children. The shock waves are therefore absorbed less by the surrounding tissue and organs, reaching the stone with less loss of energy, so that the therapeutic effect of the shock waves is greater $[30,31]$.

The common complications of P-ESWL include PEP, bleeding, infection, steinstrasse, and perforation ( Table 1) [11]. In this study, the same intensity of shock wave was applied in both adult and pediatric patients, and significant differences were not observed in the complication rate. In addition, anesthesiarelated complications and arrhythmia were not observed in any

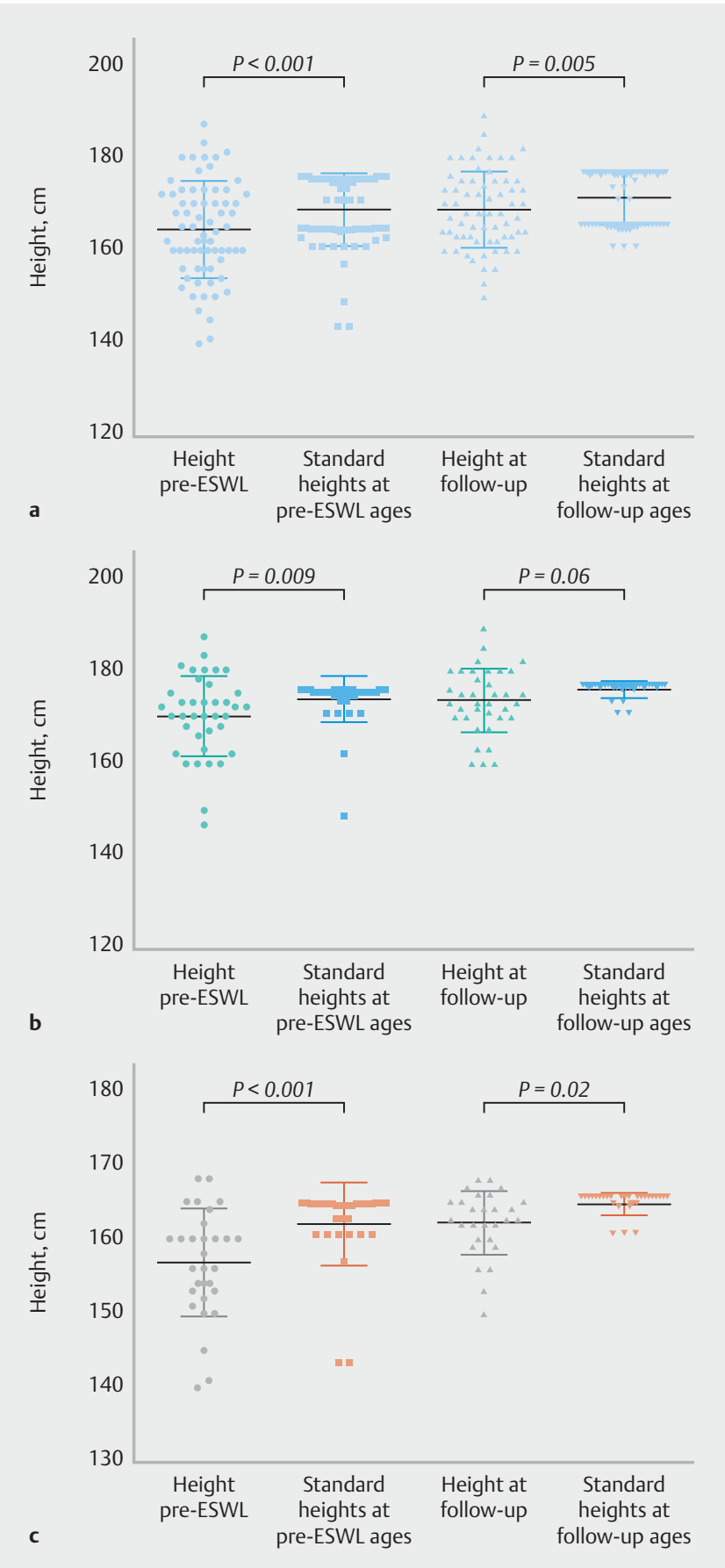

- Fig. 2 The effect of having chronic pancreatitis and of pancreatic extracorporeal shock wave lithotripsy (P-ESWL) on growth in the pediatric group. All comparisons are made with standard heights for the same ages. a Heights of the children $(n=67)$ before P-ESWL $(P<0.001)$ and at the end of follow-up $(P=0.005)$. b Heights of the boys $(n=38)$ before P-ESWL $(P=0.009)$ and at the end of follow-up $(P=0.06)$. $\mathrm{c}$ Heights of the girls $(n=29)$ before P-ESWL $(P<0.001)$ and at the end of follow-up $(P=0.02)$.

of the pediatric patients. We conclude that this shock wave intensity and anesthesia method are safe for pediatric patients.

The long-term consequences of pancreatic inflammation and fibrosis in the natural disease course of chronic pancreatitis 
- Table 7 Prognostic outcomes of pancreatic extracorporeal shock wave lithotripsy (P-ESWL) treatment in the pediatric group.

\begin{tabular}{|c|c|c|c|}
\hline & Pre-ESWL $(n=67)$ & Post-ESWL $(n=67)$ & $P$ value \\
\hline Pain frequency ${ }^{1}, \mathrm{n}$ & & & $<0.001$ \\
\hline . 0 & 0 & 45 & \\
\hline - 1 & 50 & 22 & \\
\hline . 2 & 13 & 0 & \\
\hline . 3 & 4 & 0 & \\
\hline VAS pain score ${ }^{2}, \mathrm{n}$ & & & $<0.001$ \\
\hline - 0 & 0 & 42 & \\
\hline . $1-3$ & 5 & 10 & \\
\hline . $4-6$ & 17 & 12 & \\
\hline - $7-10$ & 45 & 3 & \\
\hline Median number of days absent from school (range) & $\begin{array}{l}40.0 \\
(4.0-334.0)\end{array}$ & $\begin{array}{l}0.0 \\
(0.0-120.0)\end{array}$ & $<0.001$ \\
\hline Mean \pm SD quality of life score ${ }^{3}$ & $60.4 \pm 20.7^{1}$ & $83.7 \pm 11.3^{1}$ & $<0.001$ \\
\hline \multicolumn{4}{|l|}{ Mean \pm SD SF-36 quality of life score ${ }^{4}$} \\
\hline - Physical health component & $63.8 \pm 16.9$ & $72.9 \pm 15.1$ & 0.03 \\
\hline - Mental health component & $68.0 \pm 14.7$ & $71.7 \pm 11.1$ & 0.31 \\
\hline Mean weight \pm SD, $\mathrm{kg}$ & $51.7 \pm 14.4$ & $58.7 \pm 13.0$ & 0.001 \\
\hline Mean height \pm SD, cm & $163.7 \pm 11.4$ & $167.9 \pm 8.5$ & 0.04 \\
\hline Mean body mass index $\pm \mathrm{SD}, \mathrm{kg} / \mathrm{m}^{2}$ & $19.0 \pm 3.8$ & $20.7 \pm 3.6$ & 0.002 \\
\hline Steatorrhea, $\mathrm{n}$ & 4 & 7 & \\
\hline Diabetes, $\mathrm{n}$ & 4 & 4 & \\
\hline \multicolumn{4}{|c|}{$\begin{array}{l}\text { VAS, visual analog scale; SD, standard deviation; SF- } 36,36 \text {-item short-form general health survey. } \\
{ }^{1} \text { Pain frequency was classified into four levels: } 0 \text {, no pain; } 1 \text {, several times a year; } 2 \text {, several times a month; } 3 \text {, several times a week. } \\
{ }^{2} \text { The VAS ranges from } 0 \text { to } 10 \text {, with higher scores indicating more severe pain. } \\
{ }^{3} \text { Quality of life scores range from } 0 \text { to } 100 \text {, with higher scores indicating better quality of life. } \\
{ }^{4} \text { SF-36 physical and mental health component scores range from } 0 \text { to } 100 \text {, with higher scores indicating better physical and mental }\end{array}$} \\
\hline
\end{tabular}

will invariably lead to exocrine pancreatic insufficiency (EPI) and diabetes. If EPI develops, children may develop steatorrhea, weight loss, and fat-soluble vitamin deficiencies (vitamins $\mathrm{A}$, $D, E$, and $K)$, and these changes retard the growth and development of children [5]. Our study revealed that the height of the boys pre-ESWL was significantly lower than the standard heights for their ages $(P=0.009)$, and similar results were noted for the girls $(P<0.001)$. These results indicate that chronic pancreatitis affects the growth of children. Pancreatic enzymes were prescribed for all of the pediatric patients according to the EPI guidelines [32, 33]. At follow-up, the height of the girls remained low compared with the standard heights for their ages $(P=0.02)$; however, significant differences were no longer detected in the boys $(P=0.06)$ ( $\mathbf{F i g} .2)$. This finding can be attributed to the fact that girls grow fastest from 9 to 11 years of age and achieve $95 \%$ of their final height by the age of 13 [34]. However, girls with chronic pancreatitis were heavily affected by the disease during the above period because the average age of onset for chronic pancreatitis was $9.9 \pm 4.8$ years and they did not receive P-ESWL until they were $15.2 \pm 2.2$ years old.
There are several limitations of our study. First, given the observational study design (cohort study), there is an inherent selection bias and the follow-up data for the entire control group were not acquired; however, we believe that the matched control comparison and the self-control comparison between preESWL and post-ESWL provide persuasive evidence. Second, multiple confounders are present that can affect the growth of children in this age group and a longer length of follow-up is needed to better evaluate the prognosis of the children. Third, lack of genetic testing data prevents more intensive study of the disease. Fourth, the need for an ERCP post-ESWL is still controversial and this requires there to be a large-scale multicenter randomized controlled trial. Furthermore, a prospective study is necessary to compare the outcome of the PESWL strategy with pancreatic surgery, as several studies have reported satisfying results for pancreatic surgery in pediatric patients with chronic pancreatitis $[13,14,35]$.

In conclusion, P-ESWL is a minimally invasive, safe, and effective procedure for the management of pediatric pancreatic stones. For these patients, P-ESWL can safely achieve signifi- 
cant pain relief and stone clearance. Moreover, the therapy promotes growth and development in these pediatric patients, especially in the boys.

\section{Competing interests}

None

\section{References}

[1] Yadav D, Timmons L, Benson JT et al. Incidence, prevalence, and survival of chronic pancreatitis: a population-based study. Am J Gastroenterol 2011; 106: $2192-2199$

[2] Spanier B, Bruno M], Dijkgraaf MG. Incidence and mortality of acute and chronic pancreatitis in the Netherlands: a nationwide recordlinked cohort study for the years 1995-2005. W J Gastroenterol 2013; 19: $3018-3026$

[3] Hirota M, Shimosegawa T, Masamune A et al. The sixth nationwide epidemiological survey of chronic pancreatitis in Japan. Pancreatology $2012 ; 12: 79-84$

[4] Schwarzenberg S], Bellin M, Husain SZ et al. Pediatric chronic pancreatitis is associated with genetic risk factors and substantial disease burden. J Pediatr 2015; 166: 890 - 896.e891

[5] Kolodziejczyk E, Wejnarska K, Dadalski M et al. The nutritional status and factors contributing to malnutrition in children with chronic pancreatitis. Pancreatology 2014; 14: 275-279

[6] Chowdhury SD, Chacko A, Ramakrishna BS et al. Clinical profile and outcome of chronic pancreatitis in children. Ind Pediatr 2013; 50: $1016-1019$

[7] Wang W, Liao Z, Li ZS et al. Chronic pancreatitis in Chinese children: etiology, clinical presentation and imaging diagnosis. J Gastroenterol Hepatol 2009; 24: $1862-1868$

[8] Agarwal J, NageshwarReddy D, Talukdar R et al. ERCP in the management of pancreatic diseases in children. Gastrointest Endosc 2014; 79: $271-278$

[9] Maydeo A, Soehendra N, Reddy N et al. Endotherapy for chronic pancreatitis with intracanalar stones. Endoscopy 2007; 39: 653 - 658

[10] Majumder S, Chari ST. Chronic pancreatitis. Lancet 2016; 387: 1957 1966

[11] Dumonceau JM, Delhaye M, Tringali A et al. Endoscopic treatment of chronic pancreatitis: European Society of Gastrointestinal Endoscopy (ESGE) Clinical Guideline. Endoscopy 2012; 44: 784-800

[12] Hsu RK, Draganov P, Leung JW et al. Therapeutic ERCP in the management of pancreatitis in children. Gastrointest Endosc 2000; 51: $396-400$

[13] Rollins MD, Meyers RL. Frey procedure for surgical management of chronic pancreatitis in children. J Pediatr Surg 2004; 39: 817- 820

[14] Iqbal CW, Moir CR, Ishitani MB. Management of chronic pancreatitis in the pediatric patient: endoscopic retrograde cholangiopancreatography vs operative therapy. J Pediatr Surg 2009; 44: 139-143; discussion 143

[15] Li ZS, Wang W, Liao Z et al. A long-term follow-up study on endoscopic management of children and adolescents with chronic pancreatitis. Am J Gastroenterol 2010; 105: 1884 - 1892

[16] Tandon RK, Sato N, Garg PK. Chronic pancreatitis: Asia-Pacific consensus report. J Gastroenterol Hepatol 2002; 17: 508 - 518
[17] Li BR, Liao Z, Du TT et al. Risk factors for complications of pancreatic extracorporeal shock wave lithotripsy. Endoscopy 2014; 46: 1092 1100

[18] Yang YG, Hu LH, Chen H et al. Target-controlled infusion of remifentanil with or without flurbiprofen axetil in sedation for extracorporeal shock wave lithotripsy of pancreatic stones: a prospective, open-label, randomized controlled trial. BMC Anesthesiol 2015; 15: 161

[19] Dumonceau JM, Garcia-Fernandez FJ, Verdun FR et al. Radiation protection in digestive endoscopy: European Society of Digestive Endoscopy (ESGE) guideline. Endoscopy 2012; 44: 408-421

[20] Bloechle C, Izbicki JR, Knoefel WT et al. Quality of life in chronic pancreatitis-results after duodenum-preserving resection of the head of the pancreas. Pancreas 1995; 11: 77-85

[21] Cahen DL, Gouma DJ, Nio Y et al. Endoscopic versus surgical drainage of the pancreatic duct in chronic pancreatitis. NEJM 2007; 356: 676684

[22] Seven G, Schreiner MA, Ross AS et al. Long-term outcomes associated with pancreatic extracorporeal shock wave lithotripsy for chronic calcific pancreatitis. Gastrointest Endosc 2012; 75: 997 - 1004 e1001

[23] Tandan M, Reddy DN, Santosh D et al. Extracorporeal shock wave lithotripsy and endotherapy for pancreatic calculi-a large single center experience. Ind J Gastroenterol 2010; 29: 143-148

[24] Hu LH, Ye B, Yang YG et al. Extracorporeal shock wave lithotripsy for Chinese patients with pancreatic stones: a prospective study of 214 cases. Pancreas 2016; 45: 298-305

[25] Li BR, Liao Z, Du TT et al. Extracorporeal shock wave lithotripsy is a safe and effective treatment for pancreatic stones coexisting with pancreatic pseudocysts. Gastrointest Endosc 2016; 84: 69-78

[26] Oracz G, Pertkiewicz J, Kierkus J et al. Efficiency of pancreatic duct stenting therapy in children with chronic pancreatitis. Gastrointest Endosc 2014; 80: 1022 - 1029

[27] Inui K, Tazuma S, Yamaguchi T et al. Treatment of pancreatic stones with extracorporeal shock wave lithotripsy: results of a multicenter survey. Pancreas 2005; 30: $26-30$

[28] Moole H, Jaeger A, Bechtold ML et al. Success of extracorporeal shock wave lithotripsy in chronic calcific pancreatitis management: a metaanalysis and systematic review. Pancreas 2016; 45: 651-658

[29] Kumar S, Ooi CY, Werlin S et al. Risk factors associated with pediatric acute recurrent and chronic pancreatitis: lessons from INSPPIRE. JAMA Pediatr 2016; 170: $562-569$

[30] Longo JA, Netto Junior NR. Extracorporeal shock-wave lithotripsy in children. Urology 1995; 46: 550-552

[31] Kurien A, Symons S, Manohar T et al. Extracorporeal shock wave lithotripsy in children: equivalent clearance rates to adults is achieved with fewer and lower energy shock waves. BJU Int 2009; 103: 81 - 84

[32] de-Madaria E, Abad-Gonzalez A, Aparicio JR et al. [Recommendations of the Spanish Pancreatic Club on the diagnosis and treatment of chronic pancreatitis: part 2 (treatment)]. Gastroenterol Hepatol 2013; 36: $422-436$

[33] Toouli ], Biankin AV, Oliver MR et al. Management of pancreatic exocrine insufficiency: Australasian Pancreatic Club recommendations. Med J Aus 2010; 193: 461-467

[34] Li H, Ji CY, Zong XN et al. [Height and weight standardized growth charts for Chinese children and adolescents aged 0 to 18 years]. Zhonghua Er Ke Za Zhi 2009; 47: 487-492

[35] Weber TR, Keller MS. Operative management of chronic pancreatitis in children. Arch Surg 2001; 136: 550-554 